\title{
A formação continuada segundo os (as) professores (as) do ensino médio no norte do Tocantins: forma, finalidade e conteúdo
}

\author{
Hélida Brilhante de Jesus Queiroz ${ }^{1}$ \\ Cleomar Locatelli ${ }^{2}$
}

\begin{abstract}
Resumo
O presente artigo trata da formação continuada para os (as) professores (as) da educação básica. O objetivo é analisar as concepções e as possíveis indicações para o desenvolvimento profissional permanente a partir da/na manifestação dos (as) professores (as) do ensino médio. O estudo coletou informações junto ao quadro docente da rede estadual de ensino do norte do Tocantins, aplicando 110 questionários. As respostas revelam que, para a maioria dos participantes da pesquisa, a formação continuada deve complementar o processo formativo, sendo aperfeiçoamento ou aprimoramento profissional, realizada no médio prazo e em espaço escolar. Os principais interesses de estudos são os temas específicos das áreas de conhecimento e aqueles relativos às especificidades do trabalho docente.
\end{abstract}

Palavras-chave: Formação Continuada; Docência; Percepções; Expectativas.

\section{Continuing education according to high school teachers in northern Tocantins: form, purpose and content}

\section{Abstract}

This study deals with continuing education for teachers of basic education. The objective is to analyze the conceptions and possible guidelines for the development of continuing education in the manifestation of high school teachers. The study collected information from teachers in the state school system, applying 110 questionnaires. The answers reveal that, for most of the professors participating in the research, continuing education should serve for professional improvement, it should be carried out in the medium term and in the school space. It also reveals that the interests of studies are the specific themes of the areas of knowledge and others of a more general character, such as the use of media in the classroom, work with technological means and the development of skills. Keywords: Continuing Education; Teaching; Perceptions; Expectations.

\section{Introdução}

Na contemporaneidade a formação continuada de professores (as) tem se colocado como uma questão fundamental na busca da transformação dos atores em sala de aula. Percebe-se a complexidade e a importância desta temática na medida em que envolve o trabalho docente e o espaço escolar com toda a sua dinâmica e especificidade.

O presente estudo, resultado de reflexões a partir de uma dada realidade, apresenta

\footnotetext{
${ }^{1}$ Secretaria de Estado do Tocantins, Tocantinópolis -TO, helidabri@hotmail.com.

2 Universidade Federal do Tocantins (UFT), Tocantinópolis - TO, locatelli@uft.edu.br.
} 
conceitos, finalidades e projeções de como deve acontecer a formação continuada, tendo em vista a manifestação dos (as) próprios (as) professores (as). Mesmo sem a pretensão de ser conclusivo, o trabalho pode contribuir para a indicação de caminhos sobre o desenvolvimento profissional docente, considerando as concepções dos envolvidos e sendo ponto de partida para novas reflexões.

No conjunto do estudo, tratamos da formação continuada em seus aspectos conceituais e, sobretudo, buscamos a compreensão do tema no sentido de estabelecer uma conexão com a construção da identidade e da autonomia docente, entendendo o processo de formação docente como uma ação contínua, apoiada na definição de desenvolvimento profissional (VAILLANT; MARCELO, 2012). Portanto, compreende-se que a formação se constitui como parte intrínseca ao próprio trabalho docente.

De maneira geral, embora se depositem grandes expectativas na formação continuada, trata-se de uma questão com diversos aspectos a serem resolvidos, desde um volume baixo de iniciativas até a compreensão dos professores (as), passando pela sua relação com a valorização profissional, suas modalidades e possíveis resultados.

Para melhor compreensão do trabalho, nossa exposição está estruturada pelos seguintes eixos de discussão: na primeira parte tratamos dos aspectos conceituais da formação continuada, considerando suas possíveis relações com a construção da identidade e da autonomia docente; na segunda parte relacionamos as concepções e orientações de formação continuada segundo o Plano Nacional de Educação (PNE/2014), referente à meta 16, o Plano Estadual de Educação (PEE/2015), meta 20 e a Base Nacional Comum Curricular (BNCC); na terceira parte do trabalho apresentamos a metodologia e a caraterização dos participantes da pesquisa e; na quarta e última parte, apresentamos as concepções e orientações para formação continuada de acordo com os participantes, resultado da análise dos questionários respondidos pelos (as) professores (as).

\section{Formação continuada: aspectos conceituais}

A expressão 'formação continuada' tem sido utilizada com frequência nas escolas, nas redes de ensino e nos programas e projetos oficiais do governo para designar uma parte importante da formação dos professores (as). Normalmente se procede uma distinção básica 
que diferencia a preparação que habilita para o ingresso na carreira do magistério e aquela que se faz necessária no decurso da ação, diante dos desafios do trabalho docente na prática. A primeira, normalmente, é denominada de formação inicial e a segunda de formação continuada. No entanto, a compreensão que se tem sobre esse último tipo de formação, que pode atender a diversos objetivos, realiza-se de diversas maneiras e em variados formatos, ou seja, resulta em diferentes definições.

Castro e Amorim (2015) alertam para compreensões divergentes que se podem ter de formação continuada quando esta é relacionada à expressão 'educação premente'. Ou seja, os autores ressaltam que dependendo da perspectiva adotada, essas duas definições vão se afastar ou se aproximar. Segundo os autores, tomando os termos de maneira distinta,

[...] o conceito de educação continuada aproxima as ações de uma lógica escolarizante, de transferência de conhecimento. Em sentido oposto formação continuada desenvolver-se-ia menos sob a perspectiva de um programa escolar e mais de acordo com uma vertente de treinamento, para a qual se pressupõe que os educandos devem e podem ser treinados a fim de melhorarem seu desempenho (CASTRO; AMORIM, 2015, p.39).

No entanto, quando aproximamos as duas expressões, conforme os autores, teremos uma compreensão diferente, permitindo à formação continuada escapar da ideia de um determinismo técnico, de uma visão estreita, de ações pontuais e mecânicas, para uma visão de desenvolvimento profissional premente.

Outra forma, bastante diversa de distinguir os dois conceitos seria aproximar a educação continuada da ideia de educação permanente e, por outro lado, considerar a formação continuada como o processo de desenvolvimento profissional dos sujeitos, para o qual uma dimensão experiencial, e não apenas técnica, deve ser alcançada (CASTRO; AMORIM 2015, p.39).

Tais definições também nos levam a refletir na relação entre os modelos de formação continuada e a compreensão que se tem do próprio trabalho docente. Em outras palavras, uma visão reducionista que reproduz a ideia de um trabalho fragmentado, descontextualizado ou puramente técnico, tende a buscar formações aligeiradas, com caráter de treinamento e, normalmente, alocadas na forma do ambiente de trabalho. 
Analisando por uma perspectiva históricas, percebemos que a formação continuada docente tem encontrado finalidades e se estruturado de maneiras diversas ao longo do tempo no Brasil. Santos e Batista Neto (2016) identificam duas importantes fases da configuração da formação continuada docente na realidade brasileira das últimas décadas: a primeira entre os anos 1970 a 1980 e a segunda dos anos 1990 em diante.

Na primeira fase

[...] ao longo das décadas de 1970 e 1980, os professores foram submetidos a um modelo de formação pautado nos pressupostos da racionalidade técnica, que impunha uma visão "determinista e uniforme" sobre o seu trabalho. Esse tipo de conhecimento, referendado pela pesquisa de cunho positivista, configurou os modelos de treinamento que caracterizaram a formação continuada (SANTOS; BATISTA NETO, 2016, p.104).

Na segunda fase

A partir da década de 1990, a formação continuada inscreve suas bases numa abordagem teórica que advoga a prática pedagógica como espaço de produção do saber e, em decorrência disso, reconhece que o trabalho docente se constitui da existência de 'um conhecimento tácito, espontâneo, intuitivo, experimental, um conhecimento construído no cotidiano da prática educativa' (SCHÖN, 2000; TARDIF, 2002). Em decorrência disso, houve a valorização do pensamento reflexivo sobre a prática, e o reconhecimento dos saberes elaborados no âmbito dessa prática começa a aparecer (SANTOS; BATISTA NETO, 2016, p.104).

Em ambos os momentos as definições e tendências hegemônicas compreendem projetos de sociedade e de educação que precisam ser avaliados numa perspectiva crítica. Mesmo porque, na realidade das escolas e redes de ensino, ambas as compreensões se constituem ativas, servem ao controle a à precarização do trabalho docente.

O modelo de formação baseada na 'racionalidade técnica', cuja meta é capacitar, treinar ou aprimorar os professores (as), parte de uma concepção de docência que precisa dominar um conjunto previamente estabelecido de conteúdo, fórmulas, procedimentos. Por isso, a formação que lhe cabe no decurso de sua prática docente visa completar etapas e suprir as falhas do processo inicial, propondo e treinando novas técnicas de ensino. Para Diniz-Pereira $(2015$, p.147) "enquanto não se romper com a lógica que se baseia exclusivamente na realização de cursos de 
atualização, 'reciclagem' (sic), capacitação, entre outros, o impacto dessa formação sobre a escola e/ou a sala de aula, provavelmente, não será bastante significativa".

O modelo baseado na valorização do pensamento reflexivo, que toma a formação continuada como o espaço de construção dos saberes docente, pela vivência e pela reflexão, tende a uma atribuição de responsabilidades centrada no professor. A valorização das suas próprias descobertas, o envolvimento com os problemas da gestão e o incentivo à autoavaliação, junto a uma significativa redução das responsabilidades do Estado, elegeu o professor como a causa última dos problemas educacionais. "Com essa proposição em voga, passou a existir uma enorme valorização da prática individual, pesando sobre os professores a responsabilidade na resolução dos problemas educativos, enfatizando a individualização e a responsabilização" (GATTI et al., 2019, p.185).

Como se pode perceber, esses processos de precarização, intensificação e regulação do trabalho docente tornam mais distante a valorização, o reconhecimento e a autonomia. Como afirma Gatti (2019), o chamado professor reflexivo, requerido nos modelos de formação, propostos a partir dos anos 1990, não se desvincula de uma prática individual. Pelo contrário, reforça a competição, a autocobrança e a cobrança mútua. O efeito prático desses processos tem sido o sentimento de desprofissionalização e a perda de autonomia, "[...] entendida como condição de participar da concepção e organização de seu trabalho" (OLIVEIRA, 2004, p.1132).

\section{Formação continuada, a escola e a construção da autonomia docente}

Numa concessão diferente do que se observou nos períodos analisados acima, na pedagogia da autonomia, o ensino e a aprendizagem exigem um movimento dinâmico e dialético entre o fazer e o pensar sobre o fazer. Nesse sentido, não só os saberes que os professores (as) vão aprendendo nas suas práticas são fundamentais, como também o domínio teórico se torna essencial para a reflexão crítica.

Freire (2011) esclarece que

na formação permanente dos professores, o momento fundamental é o da 
reflexão crítica sobre a prática. É pensando criticamente a prática de hoje, ou ontem que se pode melhorar a próxima prática. O próprio discurso teórico, necessário à reflexão crítica, tem de ser de tal modo concreto que quase se confunda com a prática (FREIRE, 2011, p.40).

Sustentando esta ideia, Freire $(2011$, p.28) afirma que "o professor deve ter clareza de sua prática pedagógica e que isso demanda amplo conhecimento das diferentes dimensões que qualificam a prática pedagógica; para tanto, é necessário aprender, e aprender é construir, refletir e mudar".

Assim sendo, é fundamental que o professor não deixe de estudar para melhor enfrentar os desafios que o fazer pedagógico apresenta. É importante que a formação continuada possibilite ao professor desenvolver sua compreensão teórica da realidade para sustentar seu fazer didático pedagógico. A formação continuada, para ser coerente com essa perspectiva, deve proporcionar reflexões críticas individuais e coletivas acerca da prática docente, sendo concebida como algo inerente ao trabalho docente. Além disso, para elaboração de programas de formação continuada a serem desenvolvidos em longo prazo é importante considerar os anseios e as dificuldades apresentados pelos docentes e, que estes, sejam amparados por políticas públicas de valorização profissional.

Diniz-Pereira (2015, p.147) ressalta a importância das iniciativas “das redes públicas de ensino, em parceria ou não com as universidades, que acontecem no próprio espaço da escola, com participação ativa dos educadores na concepção e execução das mesmas". O autor defende a realização de

[...] programas de desenvolvimento profissional (e não apenas de 'formação continuada') que concebam a escola enquanto espaço de produção de conhecimentos e que concebam os educadores enquanto investigadores de suas próprias práticas, analisando, coletiva ou individualmente, e de uma maneira bastante crítica, o que acontece no cotidiano das escolas e das salas de aula brasileiras (DINIZ-PEREIRA, 2015, p.147).

Assim, compreendemos que a formação continuada deve acontecer no ambiente da escola, mas não devendo se restringir a ela. Os professores (as) devem planejar ações que acrescentem valor ao seu trabalho, considerando os aspectos científicos e sua vivência, unindo teoria e prática. 
Dessa maneira, a formação continuada vai contribuir para com esse desenvolvimento profissional contínuo. Devendo ser um espaço de apoio ao seu trabalho que é intelectual, para fortalecer sua 'capacidade de decidir' como afirma Libâneo (2004). Não deve ser confundido com uma mera arena de treinamento ou como um lugar de compensação por percursos anteriores incompletos. Também não há de ser um lugar onde se ressaltem apenas as 'competências' individuais, dando lugar a prêmios e a divulgação de 'modelos exitosos', que em grande medida estão distantes das possibilidades concretas da maioria dos (as) professores (as). Importante considerar que a formação continuada, assim como todo o trabalho escolar, constitui-se, primordialmente, um projeto coletivo. A partilha de experiências e reflexões geram aprendizados, possibilitam correções de rumos e podem contribuir para ajustar as concepções de mundo, de educação e de escola.

\section{A formação continuada no PNE/2014, no PEE/2015 e na BNCC}

No que se refere à formação continuada do professor, o Plano Nacional de Educação (PNE/2014) assegura não só a pós-graduação para 50\% dos (as) professores (as) da educação básica, como também formação continuada em sua área de atuação, considerando as necessidades, demandas e contextualizações dos sistemas de ensino.

De acordo relatório do terceiro ciclo de monitoramento das metas do Plano Nacional de Educação (BRASIL, 2020), há uma tendência de crescimento na proporção de professores (as) que realizaram formação continuada, passando de 30,6\% em 2013 para 38,3\% em 2019, um crescimento de 7,7\%. Esse dado nada nos informa sobre o tipo de formação continuada que os professores tiveram acesso. No entanto, o mero percentual para atingimento de $100 \%$ dos profissionais da educação básica já apresenta sinal de alerta pela distância que se vislumbra para atingir o que se propõe na meta.

Em nível de Brasil, no que refere às redes de ensino, em 2019, o terceiro ciclo de monitoramento das metas do Plano Nacional de Educação 2020, apresenta que

[...] as redes municipais são as que detêm os maiores percentuais de professores com formação continuada $(44,6 \%)$, seguidas pelas redes estaduais $(34,6 \%)$, privada $(31,8 \%)$ e federal $(29,0 \%)$. Esses dados indicam que, se a meta é chegar

Periódico Horizontes - USF - Itatiba, SP - Brasil - e021055 
a 100\% de profissionais da educação básica com formação continuada até 2024, haverá a necessidade de um esforço adicional das redes de ensino para o engajamento dos professores nesses cursos (BRASIL, 2020, p.344).

Não custa ressaltar também o que é estabelecido nas estratégias 16.1 e 16.2 do PNE (BRASIL, 2014) referentes à formação continuada.

16.1 realizar, em regime de colaboração, o planejamento estratégico para dimensionamento da demanda por formação continuada e fomentar a respectiva oferta por parte das instituições públicas de educação superior, de forma orgânica e articulada às políticas de formação dos Estados, do Distrito Federal e dos Municípios;

16.2 consolidar política nacional de formação de professores e professoras da educação básica, definindo diretrizes nacionais, áreas prioritárias, instituições formadoras e processos de certificação das atividades formativas;

No entanto, consultando o último relatório de monitoramento do PNE (BRASIL, 2020), percebemos não haver nenhuma indicação sobre a realização do referido 'planejamento estratégico', previsto na estratégia 16.1, nem sobre a consolidação da 'política nacional de formação de professores' conforme estratégia 16.2 .

Em consonância com o PNE, o Plano Estadual de Educação (PEE) do estado do Tocantins, na meta 20 , propõe

Instituir, no primeiro ano de vigência deste $\mathrm{PEE} / \mathrm{TO}$, programa de formação continuada para profissionais da educação básica, sob o gerenciamento do Estado, extensivo aos municípios, com a finalidade de sistematizar cursos demandados e ofertados, seja de iniciativa própria ou adesões a programas do MEC, estabelecendo monitoramento sistemático (TOCANTINS, 2015, p.39).

Dentre as estratégias estabelecidas na meta 20 no PEE/Tocantins, referente à formação continuada, destacamos:

20.1. Identificar junto aos demandantes (estadual/municipais), vagas de formação continuada para os profissionais da educação, constituindo banco de dados e informações, tendo por referência os sistemas de informação de consultas vigentes para articulação dentre os ofertantes, nas modalidades presenciais e a distância, sem prejuízo na carreira e valorização, para promoção de cursos de aperfeiçoamento, extensão e especialização;

20.2. Sistematizar e promover, em articulação com as instituições públicas de

Periódico Horizontes - USF - Itatiba, SP - Brasil - e021055 
ensino superior, a oferta da formação continuada, atendendo, no primeiro ano de vigência deste $\mathrm{PEE} / \mathrm{TO}$, todas as etapas e modalidades da educação básica e áreas de conhecimento, de forma a assegurar uma política estadual de formação continuada, garantindo a continuidade de programas nacionais e estaduais já consolidados, e políticas afirmativas de modo transversal (TOCANTINS, 2015, p.39).

Em grande medida, o PEE do Tocantins trata de fazer o diagnóstico das demandas, identificando as 'vagas de formação contínuas' e de promover a oferta no sentido de 'assegurar uma política estadual de formação continuada'. Em ambos os casos, não é clara a viabilidade de condições para que a formação continuada se realize como parte efetiva do conjunto de ações educativas. Ainda que se vislumbre alguma expectativa diante de uma possível política estadual, não se tem um direcionamento claro, de um projeto de formação continuada que venha integrar a escola, as ações educativas e a valorização docente.

No que se refere à Base Nacional Comum Curricular (BNCC), notamos que ao estabelecer uma base nacional, um assentamento curricular que deverá ser seguido em todo o território nacional, também determina, ainda que de forma indireta, o processo de formação docente. Visto que, em grande medida, a implantação de uma base curricular comum, determinando os conteúdos e os objetivos de aprendizagem, reserva para a ação docente uma tarefa mais limitada. O fazer docente tende a ser resumido muito mais no 'como ensinar' do que o 'que ensinar'.

No próprio documento que institui a Base Comum para o ensino médio, compreende-se que "A primeira tarefa de responsabilidade direta da União será a revisão da formação inicial e continuada dos professores para alinhá-las à $\operatorname{BNCC}^{\prime \prime}(2016$, p.21). Essa revisão se estabeleceu a partir da Resolução no 2, de 20 de dezembro de 2019, que “Define as Diretrizes Curriculares Nacionais para a Formação Inicial de Professores para a Educação Básica e institui a Base Nacional Comum para a Formação Inicial de Professores da Educação Básica (BNC-Formação)" (BRASIL, 2019).

A referida resolução no seu art. 6ำ apresenta os princípios relevantes para a política de formação docente. No inciso VIII, desse mesmo artigo, estabelece-se que a formação continuada,

deve ser entendida como componente essencial para a profissionalização docente, devendo integrar-se ao cotidiano da instituição educativa e considerar

Periódico Horizontes - USF - Itatiba, SP - Brasil - e021055 
os diferentes saberes e a experiência docente, bem como o projeto pedagógico da instituição de Educação Básica na qual atua o docente (BRASIL, 2019).

De acordo Bazzo e Scheibe (2019), percebe-se que a BNCC apresenta

\begin{abstract}
Uma visão tecnicista/instrumental, favorável às orientações dos grupos empresariais, interessados em formar um trabalhador que lhes fosse submisso, a partir, portanto, de um currículo próximo do que poderíamos chamar de mínimo e muito distante de uma base curricular que lhe propiciasse formação capaz de desenvolver sua autonomia e criticidade (BAZZO; SCHEIBE, 2019, p.673).
\end{abstract}

Nesse aspecto, o professor para ser eficaz deve utilizar de materiais alinhados ao referencial curricular. Os conteúdos são previamente determinados e devem ser acatados pelos (as) professores (as). É indicando a ele o que fazer e, em muitos casos, até mesmo, o como fazer, para aproximar a formação docente do conteúdo a ser trabalhado em sala de aula (BAZZO; SCHEIBE, 2019).

Assim, enquanto não se dá cumprimento ao que foi previsto no PNE (2014) e correspondentes PEE's e Planos Municipais de Educação (PME's), sem que as redes de ensino e as escolas tenham tido o tempo e as condições para avançar na execução das metas e estratégias, a formação continuada é orientada em outra direção. Agora busca-se adequação segundo as concepções e especificações da BNCC. Em grande medida, as novidades da determinação excessiva, mediante a perplexidade do quadro docente, têm ocupado grande parte dos debates e deslocado a atenção para a tarefa de se compreender o proposto.

\title{
Questões metodológicas e caraterização do público
}

Diante de uma realidade de descontinuidade na política de formação docente, os (as) professores (as), como sujeitos principais do processo, sofrem e ecoam as consequências. A mudança de foco das políticas e ações, os modelos implementados, os objetivos esperados e mesmo a ausência de ações no campo da formação, entre inúmeras outras variáveis, contribuem para que o quadro docente construa suas percepções, suas definições e expectativas. Sendo necessário ouvi-los para compreendê-los a partir de suas concepções, de suas resistências e 
aspirações. Nesse sentido, recorremos ao exame de uma realidade concreta, reunindo dados quantitativos e qualitativos, junto a um determinado grupo docente.

Especialmente no que se refere aos dados quantitativos, concordamos com Gatti (2004, p.13) que "os métodos de análise de dados que se traduzem por números podem ser muito úteis na compreensão de diversos problemas educacionais". Da mesa forma ressaltamos a importância de considerar os dados qualitativos, sobretudo para revelar a compreensão dos principais sujeitos envolvidos com a temática em estudo. Compreendendo, portanto, que a interação das abordagens nos proporciona uma visão mais próxima da realidade dos fatos.

O público-alvo da pesquisa foi os docentes da educação básica, na rede estadual do Tocantins, que atuam nas Unidades Escolares de Ensino Médio Regular, jurisdicionado à Regional de Educação de Tocantinópolis. O instrumento de coleta de dados foi um questionário aplicado através do google.com/forms, com seis questões objetivas e sete subjetivas. A aplicação do questionário se deu entre os dias 27 de outubro a 03 de novembro de 2020 . Todos os participantes da pesquisa, ao serem convidados para responderem o questionário, tiveram a opção de aceitar participar ou não, através de um Termo de Consentimento Livre e Esclarecido (TECLE). Ressaltamos ainda que o projeto de pesquisa e o questionário foram aprovados pela Gerência de Formação e Apoio à Pesquisa, da Secretaria de Estado da Educação, Juventude e Esporte, do estado do Tocantins, processo n으 2020/27000/010290.

No questionário, as questões 1 e 2 foram relacionadas à formação acadêmica dos pesquisados, a questão 3 referiu-se à atuação docente, se em sua área de formação ou não, e a 4 tratou das disciplinas que lecionaram no ano letivo de 2020.

As questões 5 e 6 referiram-se à concepção dos entrevistados quanto à formação continuada e sua finalidade. A questão 7 referiu-se ao cenário de uma atividade/ação de formação continuada que seria 'ideal' na perspectiva do participante. As questões 8, 9 e 10 estavam relacionadas à participação dos docentes em atividades/ação de formação: carga horária, temáticas abordadas e prazo de execução. Na sequência, a questão 11 tratou do local que deve acontecer a formação continuada e a questão 12 da modalidade. E, por fim, a questão 13 buscou saber das temáticas que deveriam ser consideradas prioritárias na formação continuada.

No universo de 178 docentes que fazem parte da Regional de Educação de Tocantinópolis, 110 responderam ao questionário, correspondendo $62,3 \%$ do total. 
Considerando o total dos que responderam ao questionário, 49 (44,5\%) têm acima de 15 anos de magistério, $16(14,6 \%)$ têm de 11 a 15 anos, 11 (10\%) têm de seis a dez anos e 34 (30,9\%) de um a cinco anos de magistério, portanto quase $60 \%$ dos participantes estão a mais de dez anos na atividade docente.

Com relação à formação acadêmica, 31 (28,1\%) dos participantes têm formação na área de linguagem, 13 (11\%) na área de ciências da natureza, 25 (22,7\%) na área de matemática, 22 (20\%) na área de ciências humanas, 6 (5,4\%) em pedagogia, e 14 (12,8\%) não informaram sua área de formação. Desses, $84 \%$ lecionam de acordo sua área de formação, $13 \%$ lecionam algumas disciplinas na área de formação e 3\% lecionam fora de sua área de formação.

Importante destacar ainda que uma das questões apresentada aos participantes da pesquisa os indagava sobre ter ou não participado de formação continuada, com carga horária igual ou superior a 80 horas, nos últimos três anos. Os resultados foram os seguintes: $52 \%$ responderam que sim e $48 \%$ responderam que não.

A seguir apresentamos as concepções e avaliações dos participantes sobre formação continuada. Para melhor análise das manifestações do referido quadro docente, faremos a exposição considerando três eixos de discussões: o primeiro apresenta a avaliação ou preferência dos (as) professores (as) sobre a forma, modelos ou configurações da formação continuada. O segundo apresenta o que é e qual a finalidade da formação continuada para eles. E o terceiro eixo relaciona as proposições dos (as) professores (as) para formação continuada.

\section{Sobre a forma ou modelos de organização da formação continuada}

Nesse eixo de análise revelamos a manifestação dos participantes da pesquisa sobre suas preferências: em relação ao tempo em que a formação deve ser realizada, o local da formação e a modalidade de ensino.

Na perspectiva de colher elementos que possam contribuir, não só para saber o que pensam, mas também para a elaboração de possíveis propostas (futuras) de formação continuada, atendendo aos anseios dos pesquisados, foi perguntado como a mesma deve ser organizada. $\mathrm{Na}$ opinião de 25 (22\%) dos participantes a formação continuada deve acontecer em curto prazo, 65 (59\%) em médio e 21 (19\%) em longo prazo. Como se observa no Gráfico 1, mais da metade dos 
(as) professores (as) considera ser ideal uma formação que aconteça em médio prazo.

Gráfico 1- Na sua opinião a formação continuada deve acontecer em

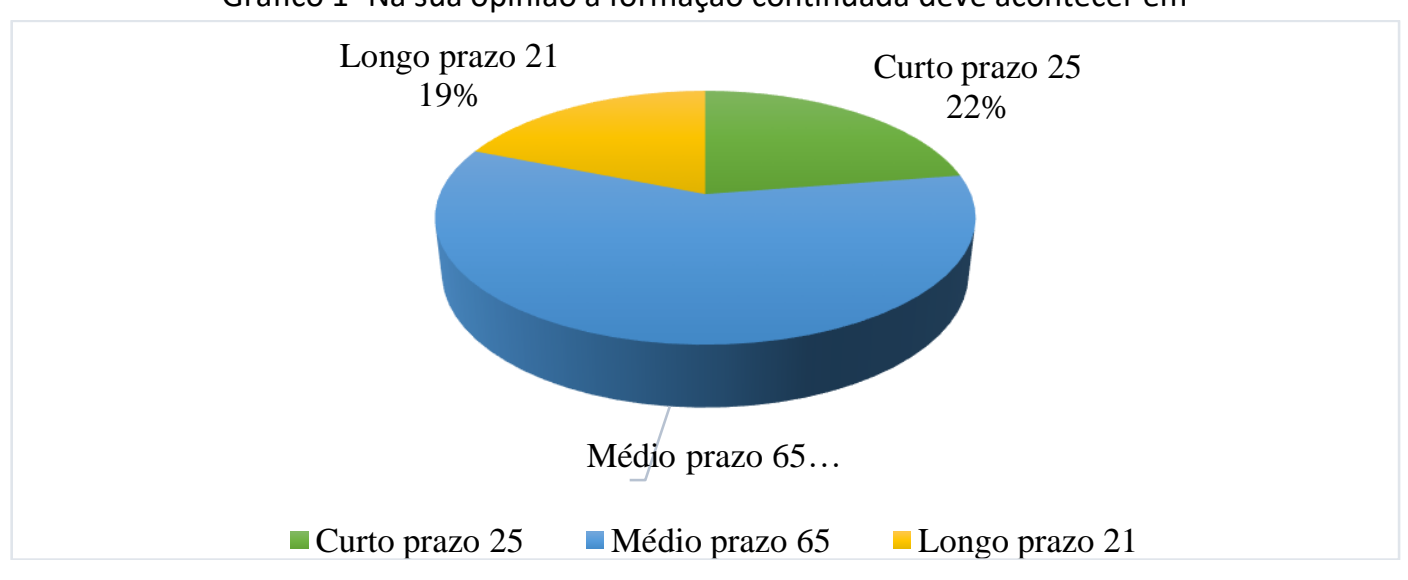

Fonte: elaboração própria com base nos questionários.

Perguntamos também sobre o lugar mais apropriado para acontecer a formação continuada. Nesse caso, com a opção para escolher uma ou duas alternativas, os participantes se manifestaram da seguinte maneira: a unidade escolar foi indicada por 68 (61,4\%), a Diretoria Regional de Ensino do Tocantins (DRET) por 38 (34,2\%), a Secretaria de Educação (SEDUC) por 16 $(14,4 \%)$ e outros ambientes foi a opção de 7 (6,3\%), como podemos observar no Gráfico 2.

Importante relembrar que a preferência pela escola como local mais adequado ou prioritário para que ocorra a formação, não diverge da defesa que fazem alguns pesquisadores da área. Este é o caso de Almeida (2006, p.86), quando afirma que "a formação continuada deve estar centrada na escola, prioritariamente".

Gráfico 2 - A formação continuada para uma efetiva contribuição ao trabalho docente, deve acontecer?

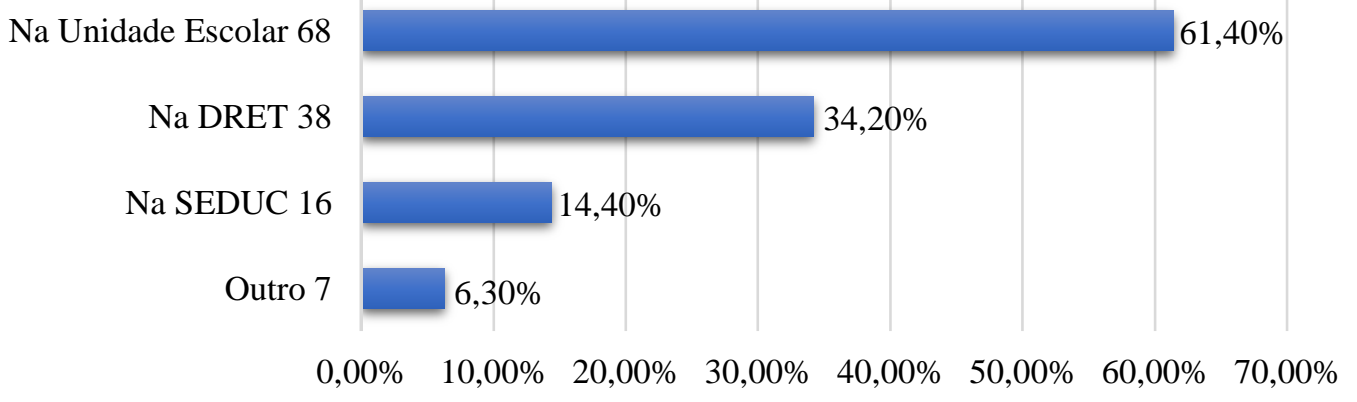

Fonte: elaboração própria com base nos questionários.

Periódico Horizontes - USF - Itatiba, SP - Brasil - e021055 
No Gráfico 3 reunimos as respostas dos participantes sobre o tipo de ensino ou modalidade preferida para a formação. Podemos verificar que indiscutivelmente os participantes da pesquisa preferem fazer formação no modelo presencial. São menos de $30 \%$ os que preferem EaD com interação e menos de $4 \%$ os que optam por um modelo híbrido, com parte presencial e parte $\mathrm{EaD}$ com interação. Essas respostas tendem a estar relacionadas, primeiramente, à questão anterior, em que a escola é vista como local de preferência para a formação continuada. Os participantes expressam também a rejeição às principais iniciativas dos últimos anos, sobretudo aquelas de iniciativa do governo federal, cuja oferta, tem sido, predominantemente, na modalidade a distância. Verificamos que a preferência por atividades presenciais pode ter relação com as dificuldades relativas aos equipamentos, à qualidade de internet, à casa sem local adequado para estudo e trabalho, entre outras limitações. Questões que se tornaram muito mais evidentes, em razão da pandemia Covid19, do mês de março de 2020 em diante, precipitando o ensino remoto obrigatório para todas as modalidades de ensino.

Gráfico 3 - Sobre a modalidade de ensino para a formação continuada

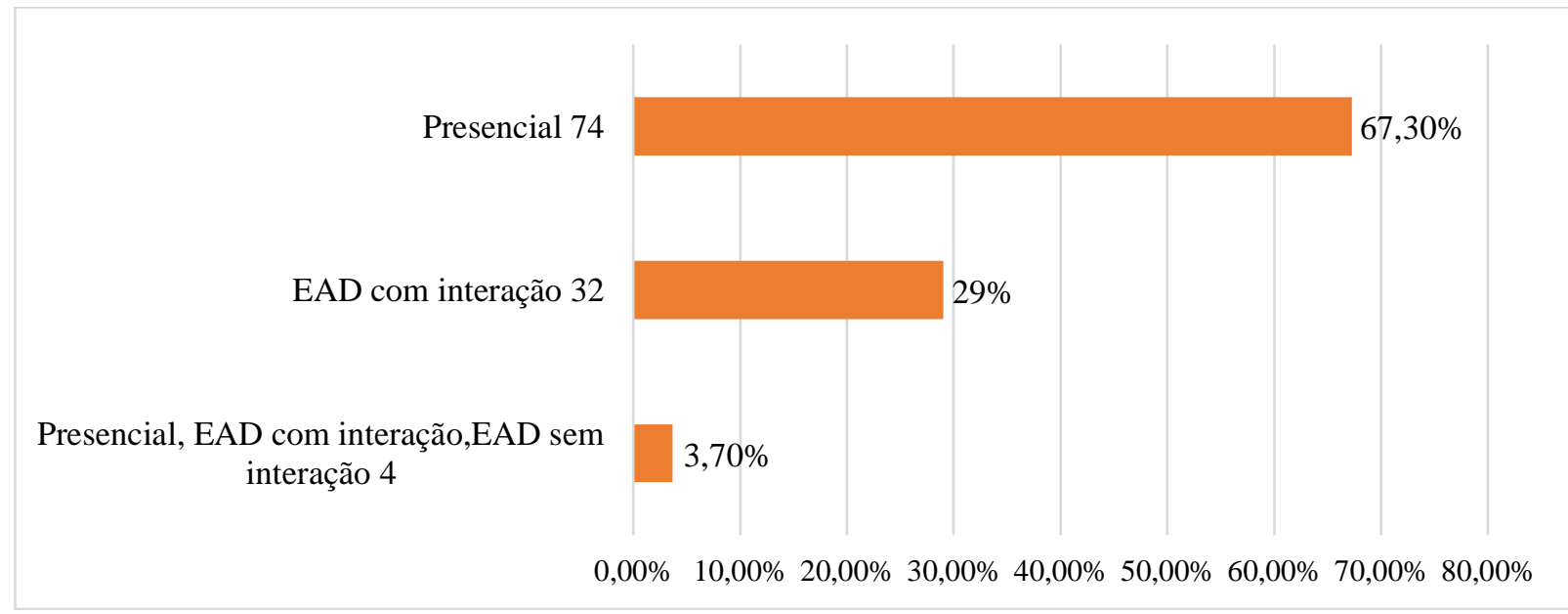

Fonte: elaboração própria com base nos questionários.

Analisado um estudo que avaliou o plano e a formação continuada de professores (as) em quatro municípios da Baixada Fluminense, envolvendo o Pró-letramento e o Gestar, Gatti (2019) verifica que algumas questões causam 'perturbações' ao processo formativo, entre estas, a autora destaca o fato desses momentos de formação serem realizados concomitantes às atividades de sala de aula, levando parte dos (as) professores (as) a não concluírem os percursos 
formativos. Compreendemos que a preferência por modelos presenciais de formação continuada e desenvolvidos na escola, como vimos na manifestação dos participantes da pesquisa, revela-se também uma reação às formações sem dispensa que ocupam os finais de semana ou outros momentos de descanso dos (as) professores (as). Esses modelos, que normalmente não consideram as condições concretas de acesso e local de estudo que cada um tem em sua casa, colocam a formação continuada no campo da individualização e de responsabilização que intensifica e precariza o trabalho docente.

\section{O que é a formação continuada e qual sua finalidade para os participantes da pesquisa?}

Pensar e fazer a formação continuada docente envolve considerar as condições situacionais e as finalidades dessa formação, os porquês, o para quê, e o para quem ela é realizada. Assim, analisando os resultados da pesquisa, é possível identificar algumas características das concepções dos pesquisados quanto ao conceito e à finalidade da formação continuada. Para melhor visualização e compreensão da manifestação dos participantes, dividimos as diferentes concepções em categorias. Sendo necessário ressaltar que a manifestação isolada de alguns dos participantes, não corresponde, necessariamente, a uma das categorias. Em alguns casos, a resposta reúne características de mais de uma das possibilidades, sendo possível constatar uma tendência predominante. Em outros casos essa tendência não fica evidente.

Categoria A - contempla a concepção dos docentes que concebem a formação continuada, como 'aperfeiçoamento/aprimoramento profissional'. Dos 110 participantes da pesquisa, 68 (61,8\%) estão inseridos nesta categoria. Neste caso, conforme as respostas obtidas, a formação continuada tem como finalidade "Aperfeiçoamentos dos saberes necessários à atividade docente, aperfeiçoar a prática pedagógica, ampliar o conhecimento" (Resposta ao questionário Prof. 1).

Categoria B - considera a concepção dos docentes que definem a formação continuada como um 'aprender constantemente/continuamente'. Nesse aspecto, 20 (18,2\%) dos pesquisados estão incluídos. Definem a formação continuada, principalmente, como um processo contínuo no sentido de 'desenvolver conhecimentos' (Resposta ao questionário prof. 
2); de 'estar sempre em constante aprendizagem para a melhoria do trabalho' (Resposta ao questionário prof. 3) ou 'Conhecimento, fato imprescindível para o profissional' (Resposta ao questionário prof. 4).

Categoria C - aqui se considera a concepção dos pesquisados que convergem no sentido de definir a formação continuada como 'meio de refletir sobre o que faz'. Dos (as) professores (as) pesquisados, dez (9\%) estão inclusos nessa categoria e definem a formação continuada como

Trocas de experiência para melhorar a aprendizagem dos alunos e minha formação profissional. Refletir sobre a prática educacional, sobre a docência, já que, é através do processo reflexivo que irá se tornar um profissional capaz de construir sua identidade, e por fim, nesta mesma linha, ter por finalidade esse processo de avaliação da prática e do conhecimento do professor, que deve ser constante, assegurando a aprendizagem significativa (Resposta ao questionário Prof. 4).

A Categoria D - corresponde a $12(11 \%)$ dos pesquisados. Nesse caso não há uma definição clara em relação à concepção de formação continuada. Observamos aqui um grupo dos participantes que não se encaixa, especificamente, em uma das categorias analisadas. Estes apresentam, de maneira geral, uma mesclagem de categorias, de maneira a não ser possível fazer uma classificação ou definir uma tendência predominante.

Em síntese, do apreendido com a manifestação dos participantes na pesquisa, constatamos três tipos de compreensão. Uma primeira, aparecendo na maior parte das manifestações, revela uma definição que concebe a formação continuada como um processo de aperfeiçoamento profissional ou um aprimoramento. Essa concepção, a nosso ver, guarda grande relação com uma visão de complementação ou atualização. Nesse caso, a preparação para docência é algo que teve um início com a formação inicial e que, apresentando carências e defasagens, precisa ser complementada e/ou modernizada. Uma segunda compreensão valoriza a ideia de formação como uma ação contínua. Concebe o trabalho docente como uma atividade peculiar que requer um diálogo permanente com o conhecimento. Nesse caso, para além de uma finalidade específica, formação continuada é algo intrínseco ao próprio trabalho docente. E um terceiro grupo que ressalta o processo reflexivo - uma ação que visa construir caminhos na observação e reorientação da própria prática. A finalidade da formação continuada é o 
monitoramento, a avaliação e autoavaliação da ação prática.

Na sua defesa do que compreende ser a finalidade da formação continuada, Gadotti (2011) não faz uma distinção entre o papel de desenvolver o aprendizado permanente ou de proceder a reflexão sob as atividades práticas, mas questiona a concepção que atribui a esta formação o objetivo de promover atualizações ou inovações. Para esse autor, ela não pode ser concebida "[...] como mera aprendizagem de novas técnicas, atualização em novas receitas pedagógicas ou aprendizagem das últimas inovações tecnológicas" (GADOTTI, 2011, p.41). Deve sim “[...] ser concebida como reflexão, pesquisa, ação, descoberta, organização, fundamentação, revisão e construção teórica [...]" (GADOTTI, 2011, p.41).

\section{As proposições dos (as) professores (as) para FC}

Para levantar as proposições dos participantes da pesquisa, inicialmente, procuramos saber o que eles projetariam como um cenário ideal de formação continuada. O conjunto de respostas a essa pergunta nos permitiu fazer os seguintes agrupamentos: um primeiro grupo apresenta proposições que nos remetem a questões relacionadas ao comportamento ou à reação dos (as) professores (as) diante da formação. Ou seja, vê como fundamental a participação de todos, os compromissos com o aprendizado e a repercussão dos aprendizados na prática. Neste campo estão 20 (18,2\%) dos participantes. Eles apresentam como cenário ideal de formação continuada questões como "A capacidade de ouvir, se comunicar e se relacionar torna-se fundamental, a fim de estabelecer uma relação de respeito e confiança com a equipes, tanto para sua carreira profissional quanto para a escola na qual trabalham" (Resposta ao questionário Prof. 5).

O segundo grupo faz referência às condições para formação: tempo/localespaço/materiais/recursos. Este grupo corresponde a 52 (47,2\%) dos pesquisados. Apresentam que o cenário ideal é "Um ambiente compatível com sua formação, por exemplo um professor de biologia, dentro de um laboratório, com instrumentos que condizem com a realidade vivenciada por cada escola", um "Local e espaço adequado com novas tecnologias que favoreçam o seu trabalho" (Resposta ao questionário Prof. 6).

O terceiro grupo está relacionado aos resultados finais da formação. Este campo está 
representado na manifestação de 28 (25,5\%) dos docentes pesquisados, que definem o cenário ideal como

\begin{abstract}
Uma formação objetiva, em que nos pautasse a desenvolver didáticas de aulas mais dinâmicas na transmissão do objeto de conhecimento das disciplinas e nos subsidiasse na detecção, de forma mais fácil, das dificuldades de aprendizagem e construção de novas estratégias para contorná-las, bem como o Estudo de metodologias diferenciadas (Resposta ao questionário Prof. 7).
\end{abstract}

O quarto grupo, representando dez $(9,1 \%)$ dos pesquisados, não descreve nenhuma ação ou caraterística capaz de revelar sua compreensão sobre o cenário ideal para formação continuada.

Ficando, portanto, evidente que são predominantes as manifestações no sentido de chamar atenção para as condições concretas em que devem ser realizadas as formações. Embora outras questões tenham sido mencionadas, em grande parte, um cenário ideal de formação continuada, para os participantes da pesquisa, se faz com as condições de tempo, local, materiais e recursos.

Por fim, perguntamos aos participantes da pesquisa sobre as temáticas que consideram prioritárias para o seu desenvolvimento profissional. Analisando o conjunto das respostas, identificamos inúmeras preferências, as quais classificamos nos seguintes grupos de proposições: a) propostas sobre o fazer docente - questões didáticas relacionadas ao planejamento, avaliação, relação professor/aluno; b) propostas de temas em áreas específicas; c) propostas de temas sobre atualidades; d) propostas de temas de gestão: avaliação institucional, projeto pedagógico, políticas educacionais, trabalho em equipe etc.; e) outros, como podemos conferir no Gráfico 4. 
Gráfico 4 - Temáticas consideradas prioritárias para formação continuada

Propostas sobre o fazer docente (43)

Propostas sobre áreas específicas (56)

Propostas sobre atualidades $(3)$

Propostas sobre temas de gestão (7)

Outros (1)
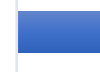

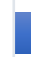

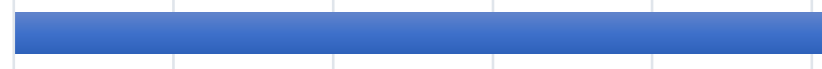

$50,90 \%$

$2,70 \%$

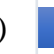

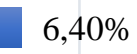

$1 \%$

$0 \%$

$10 \%$

$20 \%$

$30 \%$

$40 \%$

$50 \%$

$60 \%$

Com relação às temáticas a serem abordadas prioritariamente na formação continuada verificamos o seguinte:

- $\quad 50,9 \%$ dos docentes apresentaram como temática prioritária os temas específicos de suas áreas, relacionados aos conteúdos que ministram como biologia, matemática, língua portuguesa e outras. Por vezes agregam esses temas a outros como o uso das mídias na sala de aula, o aperfeiçoamento de como trabalhar com os meios tecnológicos e o desenvolvimento de competências e habilidades no educando;

- $39 \%$ sugeriram temas mais diretamente relacionados à profissão docente como planejamento, metodologia de ensino, avaliação da aprendizagem ou sobre a relação professor/aluno;

- $6,4 \%$ consideraram relevante a inserção na proposta de formação continuada de temáticas referentes à gestão, relacionado à organização escolar, ao projeto político pedagógico e outros;

- $2,7 \%$ dos docentes sugeriram inserir 'atualidades', como os referentes ao contexto político e econômico, às mídias, à tecnologia e redes sociais.

Diante da análise dos dados percebe-se que a formação continuada, segundo a compreensão dos participantes da pesquisa, pode responder a um amplo e variado campo de possibilidade a fim de contribuir para o processo educativo. No entanto, em grande parte, ainda se tem em mente um processo formativo que serve à superação das lacunas da formação inicial. A perspectiva dos participantes é, como vimos, predominantemente tecnicista e a maioria 
gostaria que essa formação tratasse, prioritariamente, dos temas de sua área de atuação.

Sendo assim, percebemos a necessidade de se ampliar a compreensão sobre a formação continuada junto a esse quadro docente. Conforme Candau (1996, p.150),

[ela] não pode ser concebida como um processo de acumulação (de cursos, palestras, seminários, etc., de conhecimentos ou técnicas), mas sim como um trabalho de reflexibilidade crítica sobre a prática de (re) construção permanente de uma identidade pessoal e profissional, em interação mútua.

Almejamos que esse estudo, ouvido os (as) professores (as), possibilite a ampliação do diálogo junto às autoridades educacionais e aos integrantes do magistério. Para além de buscar atendê-los em suas expectativas, que são muitas e variadas, torna-se necessário fortalecer o ideal de um processo formativo compreendido como parte intrínseca do próprio trabalho docente. Sendo necessário reconhecer também que a defesa desse princípio, assim como a rejeição dos participantes da pesquisa a modelos e modalidades que, Ihes são disponibilizados, pressupõe resistir contra a individualização e responsabilização que tende a precarizar o trabalho e a formação do (a) professor (a).

\section{Considerações finais}

Tendo em vista o conjunto do presente debate, iteramos nossa compreensão de que a formação docente pressupõe, ao mesmo tempo, o domínio teórico e a reflexão crítica da realidade escolar. Ou seja, o desenvolvimento profissional permanente não deve ser compreendido como algo exterior ou distinto em relação ao trabalho docente. Pelo seu caráter teórico-prático e pelas suas especificidades, a postura formativa, que inclui revisão críticas constante dos conteúdos e dos procedimentos didáticos-pedagógicos, precisa ser concebida como parte do labor docente.

Reiteramos que a teoria serve não só para acessar o conhecimento historicamente acumulado ou como referência para definição de objetivos, serve também para analisar a própria prática em articulação com um contexto mais amplo, que envolve a docência, a escola e a sociedade. Sem uma sólida formação teórica não se faz uma análise histórica da profissão 
docente, da escola e dos conteúdos a serem ensinados.

Os dados da pesquisa revelam a importância de ouvir os (as) professores (as) para desenvolver programas e projetos referentes à política pública de formação continuada. A pesquisa confirma que as escolas precisam de apoio na elaboração/construção de projetos de formação continuada. Estes projetos devem considerar os anseios dos professores, proporcionando espaços de reflexão coletiva, criando a cultura de análise da prática para construção de ações que proporcionem avanços no ensino e na aprendizagem.

Pensar a prática pedagógica em grupo, expondo as angústias, as descobertas e as conquistas, é fundamental para o avanço do ensino e aprendizagem. É necessário que a formação continuada proporcione ao professor estudar, refletir, se autoavaliar, avaliar o currículo, o projeto político-pedagógico e o regimento escolar. Essa formação pode ajudar a fazer escolhas sobre as atividades escolares, definir objetivos alinhados aos objetivos do professor, da escola e da transformação social almejada.

Neste sentido, analisamos a formação continuada diretamente ligada ao papel do professor; as possibilidades de transformação de suas práticas pedagógicas e das possíveis mudanças do contexto escolar. Acredita-se que o projeto de formação continuada na escola deve ser pensado e organizado de maneira que tenha significado para os participantes e, para isso, é necessário reflexão entre os pares sobre todos os aspectos que envolvem o fazer pedagógico. Além disso, torna-se necessário que se reflita sobre as próprias condições do trabalho docente, não para gerar responsabilização ou uma cultura de autoculpa, mas para que os (as) professores (as) possam enfrentar e se contrapor às definições deterministas e restritivas do seu trabalho, assumindo uma postura de sujeito, de quem faz escolhas, de quem produz e lida com o conhecimento de forma crítica. É a partir dessa perspectiva que a formação continuada pode e deve ter a escola como lócus privilegiado.

Sendo assim, a formação continuada em serviço, quando acontecer no espaço escolar deve considerar a necessidade, as condições de trabalho e o tempo dos professores. $E$, nesse sentido, o presente estudo nos leva a ressaltar, que se constitui de extrema importância, compreender e levar em consideração as concepções e as expectativas do quadro docente. Ao mesmo tempo, reafirmamos nossa convicção, de que, o resgate de um processo autêntico de desenvolvimento profissional permanente, concebido como parte intrínseca do trabalho 
docente, valorizando o domínio teórico e a reflexão crítica, poderão fazer parte de um conjunto de transformações e resistência, necessárias para construir novos horizontes e superar os obstáculos presentes.

\section{Referências}

ALMEIDA, L. R. A dimensão relacional no processo de formação docente. São Paulo: Loyola, 2006.

BRASIL. Instituto Nacional de Estudos e Pesquisas Educacionais Anísio Teixeira (Inep). Relatório do 3o ciclo de monitoramento das metas do Plano Nacional de Educação - 2020. Brasília, 2020. Disponível em: http://portal.inep.gov.br/informacao-da-publicacao//asset_publisher/6JYIsGMAMkW1/document/id/6975827. Acesso em: 13 abr. 2021.

BRASIL. Resolução no 2, de 20 de dezembro de 2019. Define as Diretrizes Curriculares Nacionais para a formação inicial de professores para a educação básica e institui a Base Nacional Comum para a formação inicial de professores da educação básica (BNC-Formação). Disponível em: http://portal.mec.gov.br/docman/dezembro-2019-pdf/135951-rcp002-19/file. Acesso em: 31 mar. 2021.

BRASIL. Ministério da Educação. Secretaria da Educação Básica. Base Nacional Comum Curricular. Brasília, DF, 2016. Disponível em: http://basenacionalcomum.mec.gov.br. Acesso em: 03 jul. 2019.

BRASIL. Presidência da República. Lei no 13.005, de 25 de junho de 2014. Aprova o Plano Nacional de Educação - PNE e dá outras providências. Brasília, DF: Presidência da República, 25 jun.2014. Disponível em: http://www.planalto.gov.br/ccivil_03/_ato20112014/2014/lei/l13005.htm. Acesso em: 26 jan.2021.

BAZZO, V.; SCHEIBE, I. De volta para o futuro... retrocessos na atual política de formação docente. Revista Retratos da Escola, Brasília, v.13, n.27, p.669-684, set./dez. 2019. Disponível em: http://retratosdaescola.emnuvens.com.br/rde. Acesso em 08 nov. 2020.

CASTRO, M. M. C.; AMORIM, R. M. A. A formação inicial e a continuada: diferenças conceituais que legitimam um espaço de formação permanente de vida. Cad. Cedes, Campinas, v.35, n.95, p.37-55, jan.-abr., 2015. Disponível em: https://www.scielo.br/pdf/ccedes/v35n95/0101-3262ccedes-35-95-00037.pdf. Acesso em: 11 nov.2020.

CANDAU, V. M. Formação continuada de professores: tendências atuais. In: REALI, A.; MIZUKAMI, M. G. N. Formação de professores: tendências atuais. São Carlos: Ed. UFSCAR, 1996, p.139-152. 
DINIZ-PEREIRA, J. E. Formação de professores, trabalho e saberes docentes. Trabalho \& Educação, Belo Horizonte, v.24, n.3, p.143-152, set-dez. 2015.

FREIRE, P. Pedagogia da autonomia: saberes necessários a prática educativa. 43. ed. São Paulo: Paz e Terra, 2011.

GADOTTI, M. Boniteza de um sonho: ensinar-e-aprender com sentido. 2. ed. São Paulo: Instituto Paulo Freire, 2011.

GATTI, B. A. Estudos quantitativos em educação. Revista educação e pesquisa, São Paulo, v.30, n.1, p.11-30, jan./abr. 2004. Disponível em: https://doi.org/10.1590/S1517-

97022004000100002. Acesso em: 07 ago. 2020.

GATTI, B. A.; BARRETTO, E. S. S.; ANDRÉ, M. E. D. A; ALMEIDA, P. C. A. Professores do Brasil: novos cenários de formação. Brasília: UNESCO, 2019.

LIBÂNEO, J. C. Organização e gestão da escola: teoria e prática. Goiânia: Alternativa, 2004.

OLIVEIRA, D. A. A reestruturação do trabalho docente: precarização e flexibilização. Educ. Soc., Campinas, v.25, n.89, p.1127-1144, set./dez. 2004. Disponível em:

http://www.cedes.unicamp.br Acesso em: 30 mar. 2021.

SANTOS, E. O.; BATISTA NETO, J. Concepções e práticas de formação continuada na educação básica. Interritórios: Revista de Educação Universidade Federal de Pernambuco, v.2, n.3, p.101120, 2016. ISSN 2525-7668. Disponível em: file://C:/Users/cleo_/Downloads/8692-16179-1SM.pdf. Acesso em: 21 de set. 2021.

TOCANTINS. Lei no 2.977, de 08 de julho de 2015. Aprova o Plano Estadual de Educação do Tocantins - PEE/TO (2015-2025), e adota outras providências. Diário Oficial do Estado do Tocantins, Palmas, n.4.411, 9 jul. 2015.

VAILLANT, D.; MARCELO, C. Ensinando a ensinar: as quatro etapas de uma aprendizagem. Curitiba: UTFPR, 2012.

Recebido em abril 2021.

Aprovado em setembro 2021. 